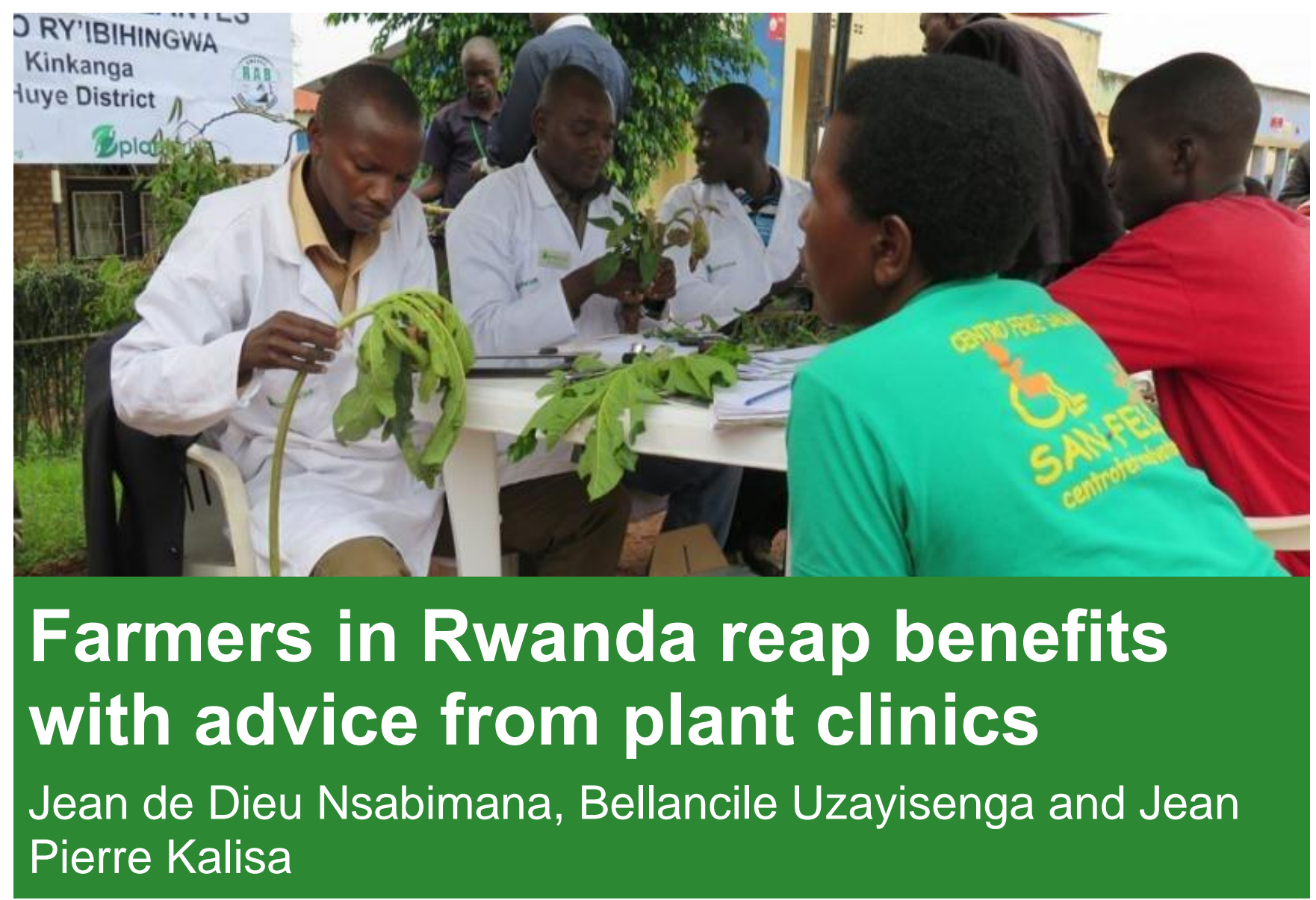

\title{
Summary
}

Plant clinics have been operating in Rwanda since 2011 when 8 were launched in the four zones of the country by the Rwanda Agriculture Board (RAB) in partnership with Plantwise. The plant clinics are intended to help smallholder farmers to manage the sometimes devastating crop diseases and pests by acting as an easily accessible source of current, timely, practical, trustworthy and cost-effective advice. In addition, as a community-based early-warning mechanism for crop problems, they are expected to generate data that give an insight into the spread and occurrence of important crop health concerns. Early notification of a devastating crop disease can save a whole harvest from destruction and can help the government to set up prevention and control measures. That was what happened with maize lethal necrosis when a plant health clinic in Byangabo in the north first recognized it in 2013. RAB and Plantwise undertook a study in 2015 involving 116 farmers, among whom 39 were regular plant clinic users, 37 were first-time users and 40 had never used the clinics, to learn how the clinics were playing their role. The study also sought to determine the nature of the interaction of the plant clinics with other services supporting farmers and the opportunities for enhancing the relationship.

\section{Key highlights}

- All the farmers who visit the plant clinics use or plan to use the advice from the plant doctors.

- Approximately $50 \%$ of the farmers who used the advice from the plant clinics saw increases of $47-$ $127 \%$ in the yield of maize, beans, banana, eggplant and pineapple.

- More men than women and more wealthy than poor farmers use plant clinics.

- Amongst the plant clinic users the preferred source of plant health information is plant doctors, while those who do not use the clinics prefer obtaining the information from neighbours.

- Almost all the plant clinic users share the advice from the plant doctors with others. 
- Plant doctors are less likely than other extension workers to recommend the use of a chemical product as a solution to a plant problem. This is a reflection of the training of plant doctors in integrated pest management, which emphasises the rational use of pesticides.

- Plant clinic users are more willing to pay for crop health advice than are individuals using other sources of advice.

\section{Why plant clinics?}

Crop intensification in Rwanda started by the government in 2007 has brought big benefits for crop production in the country. Using modern practices, farmers have seen maize, wheat and cassava production triple and bean production double, along with impressive yields for rice and Irish potatoes over about five years now. But the intensive cultivation, large-scale seed imports and monocropping required with these farming methods, plus the unchecked movement of plants and their products internally, have brought with them the dangers and conditions associated with exacerbation of crop pests and diseases.

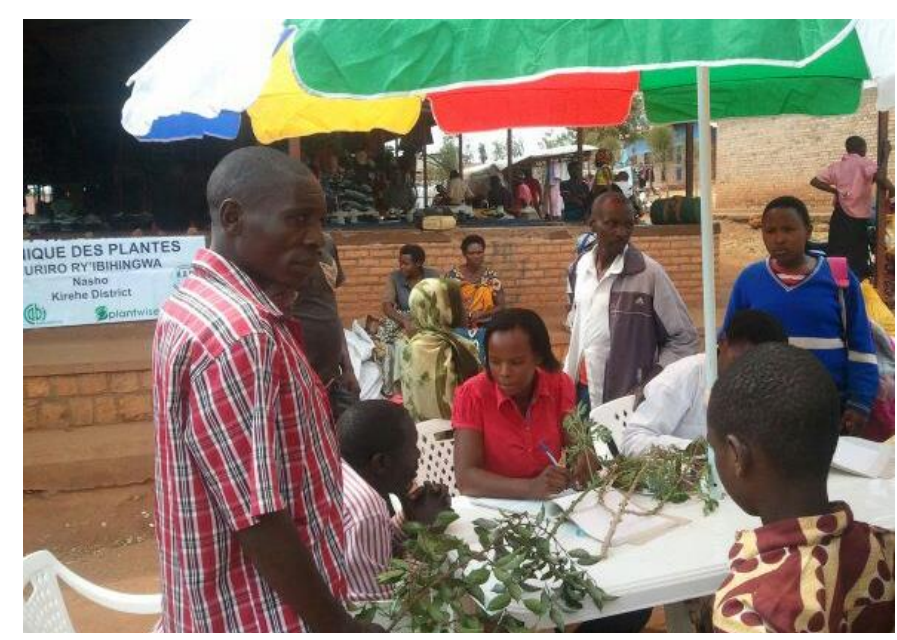

Nasho plant clinic in Kirehe District

In 2011, the Rwanda Agriculture Board (RAB) in partnership with Plantwise started plant health clinics to provide smallholder farmers with an accessible service for diagnosing plant problems and providing advice on how to tackle them, and to act as a community-based surveillance mechanism for serious pests and diseases. The data from the plant clinics provide insight into the spread and prevalence of certain crop health issues. Such information can lead to early notification of a devastating crop disease and help the government set up control measures against the disease. That was the case with maize lethal necrosis when it was first recognised at a plant health clinic in Byangabo in the north in 2013. The plant clinics have grown from the initial 8 to 65.

\section{How plant clinics work}

Plant clinics work like human clinics except that they are temporary and are set up in the open or makeshift structures in locations that are easily accessible to farmers, such as marketplaces. They have links to expert resources such as diagnostic laboratories and knowledge networks. Before a clinic session, announcements in the area around where it will be held invite farmers to bring samples of diseased plants. Mobile public address systems, community meetings, plant health rallies and the radio are used for the announcements. Generally farmers bring samples of the diseased plants, but photographs are used sometimes if there is fear that the sample will be damaged in transit. A wide variety of crops are seen at the clinics, with maize as the most common.

Besides guiding farmers on how to deal with their immediate problem, the plant doctors give advice on prevention of the problem. Their service includes follow-up field visits to diagnose the problem if the sample brought to the clinic was not adequate or to get a sample for laboratory analysis. Although government extension officers, agro-dealers and other agencies also are helping farmers with crop health issues, plant health clinics have a unique niche in that their advice is based on the principles of integrated pest management. Their solution for a crop problem includes a variety of choices where others provide a single option, and they are less likely to recommend a commercial product such as a pesticide as a solution. Agro-dealers recommend the products they sell.

\section{Why plant clinics work}

The plant clinics have come to be considered by farmers who use them as trustworthy and to be offering a service with value. The fact that it is the richer farmers with the larger land parcels and 
bigger domestic animal herds who mostly use them is vindication of their worth. The farmers' high regard for the plant doctors is the main factor in their satisfaction with the plant clinic services. They see the plant doctors as competent and technically knowledgeable to diagnose their plant problems and to provide adequate solutions to tackle them. This is also the reason the clinics are ranked first as the source of plant health information by those who use them.

"Before the plant clinic initiative, I was losing about 60 per cent of my produce each season. It was unbearable because I could not even recoup the investment on the farm; however, since I started getting advice on disease management, losses have declined to 20 per cent."

Dominique Nkundukozera, a farmer in Rusatira Sector in Huye District (http://www.newtimes.co.rw/section/ article/2016-01-22/196327/).

The plant doctors' commitment to their work, demonstrated by their excellent service delivery skills, gives farmers the incentive to use the clinics. The doctors are available when the farmers arrive at the clinic and they carefully listen to their problems, taking the time to help them understand the diagnosis, the solution and their written directions. The solutions offered are considered practical, and almost all farmers can cover the cost to fully implement them and in nearly all cases do adopt them. The fact that up to $97.4 \%$ of the regular plant clinic users and $94.6 \%$ of first-time clients were willing to pay a small fee for the services is an indication of the value attached to the plant clinics. All plant clinic users share the advice with others (see table 1).

Table 1. People with whom farmers shared or would share plant clinic advice

\begin{tabular}{lcc}
\hline Who the clinic users share advice with & Regular plant clinic users & First-time plant clinic users \\
\hline Farmer's household & 2 & 5 \\
Farmers' group & 36 & 3 \\
Lead farmer & 1 & 0 \\
Neighbours & 0 & 28 \\
No one & 0 & 1 \\
Total & 39 & 37 \\
\hline
\end{tabular}

The importance accorded to the plant clinics is not misplaced. By rigorously following their advice, some farmers have seen impressive benefits. According to the study, 50\% of such farmers realised increases of $47-127 \%$ in the yields for maize, beans, banana, eggplant and pineapple (figure 1).

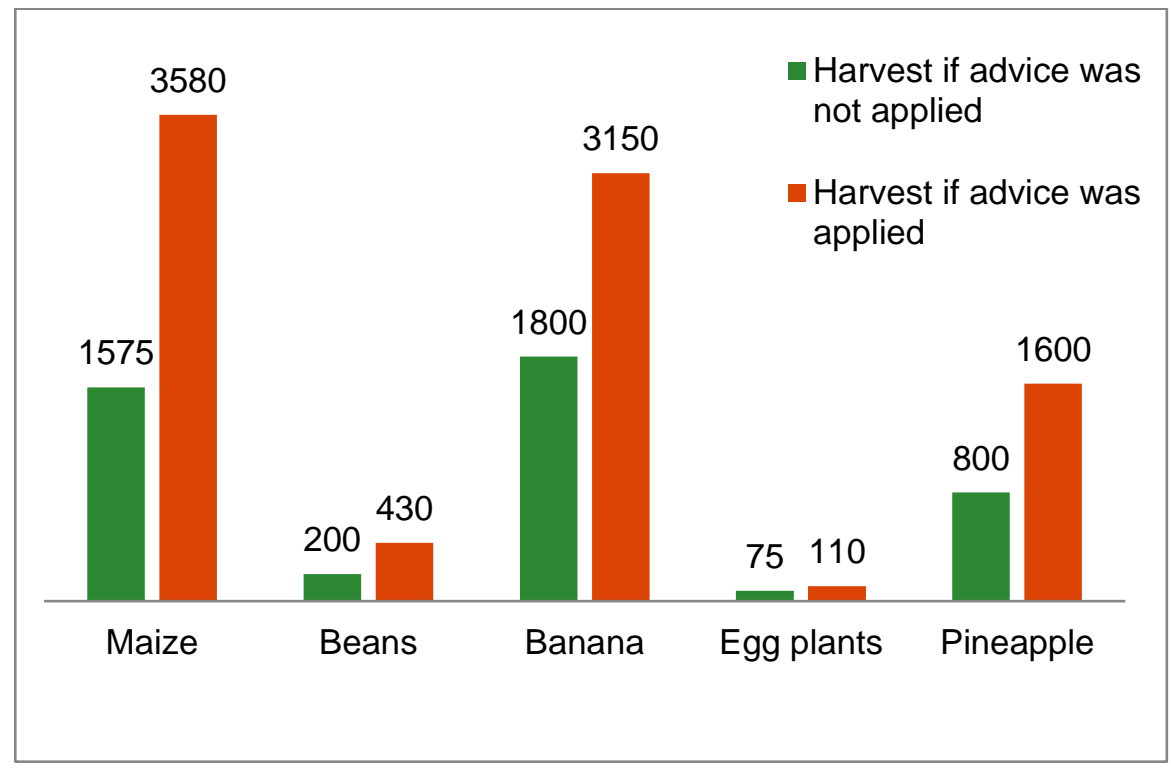

Figure 1. Crop production change according to plant clinic users (kg). 


\section{Way forward}

Despite the high regard for the plant clinics, awareness on them among farmers in Rwanda is very low. In this study, $84.2 \%$ of the farmers who did not use the plant clinics had never heard of them. Sensitisation about them could be improved by involving local authorities and using community forums and plant clinic users in their promotion.

The plant clinics' logistics require careful thinking through, taking into account farmers' circumstances. The clinics' accessibility is low, and in the study $67 \%$ of the farmers who use them considered it unsatisfactory. For a quarter of these farmers, distance was an issue. More doctors and working sessions are required, especially during the crop growing season. Two sessions a month is not enough. Weather conditions hamper operation of the plant clinics.

Ways are needed to foster plant clinic use among women, who form the bulk of the smallholder farmers yet hardly use the clinics compared with men. More female plant doctors should be used and the clinics should be located where women can conveniently reach them instead of marketplaces, which are frequented mostly by men. This should take into account that women's work ties them to the home.

Often a farmer's field has more than one problem and application of the plant doctor's advice may not be an adequate solution. Or a disease might affect more than one crop but the farmer takes only one sample to the clinic, meaning that the diagnosis will not be complete. Also the treatment recommended might damage adjacent crops. A mechanism is needed to complement plant clinics' work in order to address issues such as these.

When cultural practices cannot solve a crop problem, plant doctors recommend chemicals. But these can be expensive and sometimes are not available. It would help if the clinics stocked commonly used chemicals or were set up close to agro-dealer shops. Providing farmers with an updated list of approved chemicals will help their interaction with agro-dealers.

Plant clinics are collaborating with other agencies supporting farmers, which mostly mobilise farmers for the clinics, supply the products recommended by plant doctors or refer farmers to the clinics, as well as with other government agencies. Formalising these relationships will bring efficiency to the extension system by defining each partner's role. In addition, crop health information from the plant clinics could be incorporated into messages delivered through plant health rallies and other extension services as a part of a cohesive arrangement to support farmers.

\section{Additional information and resources}

Nsabimana, J.D.D., Uzayisenga B., Kalisa, J.P. (2015). Learning from plant health clinics in Rwanda. Plantwise internship report. 


\section{Acknowledgements}

$\mathrm{CABI}$ is an international intergovernmental organisation, and we gratefully acknowledge the core financial support from our member countries (and lead agencies) including the United Kingdom (Department for International Development), China (Chinese Ministry of Agriculture), Australia (Australian Centre for International Agricultural Research), Canada (Agriculture and Agri-Food Canada), Netherlands (Directorate-General for International Cooperation), and Switzerland (Swiss Agency for Development and Cooperation).

\section{Project donors}

Plantwise is supported by:

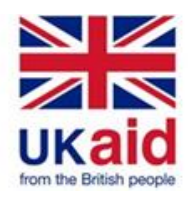

Irish Aid

Rialtas na hÉireann Government of Ireland

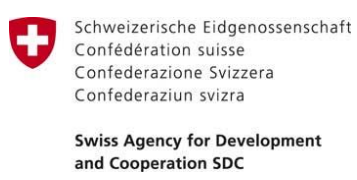
and Cooperation SDC

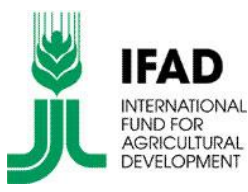

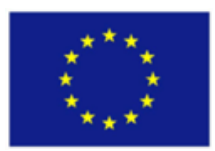

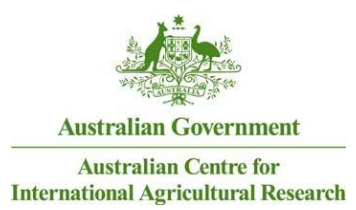

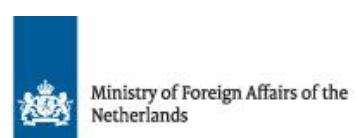

Ministry of Agriculture and Rural Affairs (MARA)

People's Republic of China

\section{Project partners}
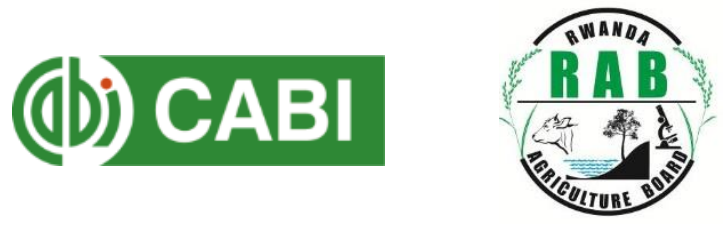

\section{Authors}

Jean de Dieu Nsabimana, Bellancile Uzayisenga and Jean Pierre Kalisa

Plantwise Country Coordinator: Martin Kimani

Plantwise National Coordinator in Rwanda: Bellancile Uzayisenga

Technical Writer: Kellen Kebaara

Editorial Coordinator: Solveig Danielsen

\section{How to cite this paper}

Nsabimana, J. de D., Uzayisenga, B., Kalisa, J.P. 2016. Farmers in Rwanda reap benefits with advice from plant clinics. CABI Study Brief 14. DOI: https://dx.doi.org/10.1079/CABICOMM-62-8111 